- Assembled Siqveland matrix bands are contaminated with blood.

- Current pre-cleaning methods cannot remove blood from assembled bands.

- Siqveland matrix bands should be discarded after use on one patient.

- Blood can be removed from retainers after removal of the matrix band.

- Immersion in enzymic detergent followed by processing in an instrument washer is the most effective method of pre-cleaning for Siqveland matrix retainers.

\title{
An investigation of the decontamination of Siqveland matrix bands
}

\author{
C. L. Whitworth, ${ }^{1}$ K. Davies, ${ }^{2}$ N. O. A. Palmer ${ }^{3}$ and M. V. Martin ${ }^{4}$
}

\begin{abstract}
Objectives This study investigated blood contamination of artificially and clinically contaminated Siqveland matrix bands and retainers. A modified version of the recognised Kastle-Meyer test for blood was used to compare the efficacy of enzymatic agents, a washer-disinfector and an instrument washer for pre-sterilisation cleaning of Siqveland matrix bands and retainers.
\end{abstract}

Methods Assembled Siqveland matrix bands were contaminated either artificially with horse blood or clinically during dental treatment. Contaminated assembled matrix bands and retainers were subjected to immersion in an enzymatic agent, automated processing in a washerdisinfector or instrument washer, or a combination of pre-soaking and automatic cleaning. Residual blood contamination from each band and retainer was measured and compared to the volume of blood recovered from an unprocessed control group of contaminated assembled matrix bands or retainers.

Results Residual blood was recovered from every clinically contaminated assembled Siqveland matrix band and retainer. The volume of blood recovered from assembled Siqveland matrix bands ranged from 0.13-7.1 $\mu \mathrm{l}$ and from retainers, following removal of the matrix band, from $0.001-1.523 \mu \mathrm{l}$. The most effective method of pre-sterilisation cleaning for artificially contaminated assembled matrix bands was processing in the washer-disinfector. Conversely, the most effective method for cleaning clinically contaminated assembled matrix bands and retainers was pre-soaking in an enzymatic agent followed by a heavy-duty cycle in an instrument washer.

Conclusions It is not possible to clean assembled Siqveland matrix bands using any method currently available to dental practitioners. Matrix bands should be discarded after use on one patient. Once the band is removed, all detectable blood can be removed from the retainer by pre-soaking in an enzymatic detergent followed by processing in an instrument washer.

${ }^{1 *}$ General Dental Practitioner, Hoghton Street Dental Practice, 22 Hoghton Street, Southport, PR9 OPA; ${ }^{2}$ Senior Biomedical Scientist, ${ }^{3}$ General Dental Practitioner/Parttime Lecturer, ${ }^{4}$ Senior Lecturer, University of Liverpool, Clinical Dental Sciences, Liverpool, L69 3GN

${ }^{*}$ Correspondence to: Mrs Christine Whitworth

Email:cwblackadder@btinternet.com

Online article number E12

Refereed Paper - accepted 19 April 2006

DOI: $10.1038 /$ bdj.2007.142

${ }^{\circledR}$ British Dental Journal 2007; 202: E12

\section{INTRODUCTION}

Decontamination or disposal of dental instruments that have come into contact with oral and other body fluids is a fundamental infection control measure., ${ }^{1,2}$ Blood contaminated instruments have the potential to carry and transmit pathogenic material, including hepatitis $\mathrm{B}$ and $\mathrm{C}$ and HIV. ${ }^{3-6}$

Matrix bands become heavily contaminated with blood, saliva and plaque during clinical use. A study in Scotland reported that the Siqveland matrix band is used in most dental practices. ${ }^{7}$ Lowe et al. ${ }^{8}$ investigated residual blood contamination of Siqveland matrix bands following clinical use and decontamination in general dental practice using the Kastle-Meyer technique, ${ }^{9}$ a forensic test for blood. The techniques used for pre-sterilisation cleaning in that study were manual and ultrasonic cleaning. The authors concluded that when Siqveland matrix bands are re-processed in the assembled state, then adequate pre-sterilisation cleaning cannot be reliably achieved. It has been recommended that matrix bands be considered single use items. ${ }^{1}$ An investigation of the decontamination of dental burs concluded that enzymatic agents and washer-disinfectors are significantly more effective than manual cleaning in the decontamination of dental burs. ${ }^{10}$ A study of decontamination of clinically contaminated orthodontic molar bands showed that soaking in an enzymatic detergent, followed by autoclaving rendered all bacteria non-viable. ${ }^{11}$ This study did not test for residual blood contamination following decontamination.

No published work has investigated the efficacy of enzymatic agents, instrument washers or washer-disinfectors in the pre-sterilisation cleaning of assembled Siqveland matrix bands. There is no evidence to show that matrix band retainers can be successfully decontaminated once the band has been removed.

The purpose of this investigation was to compare the efficacy of an enzymatic agent, an instrument washer and a washerdisinfector, and combinations of these cleaning methods, in the removal of blood from assembled Siqveland matrix bands and retainers after removal of the band. 


\section{MATERIALS AND METHODS}

\section{Kastle-Meyer technique}

Residual blood contamination of Siqveland matrix bands following decontamination was detected using the Kastle-Meyer technique. ${ }^{9}$ This test relies on a colour change to demonstrate the presence of blood. Haemoglobin present in blood reacts with hydrogen peroxide to produce oxygen. The released oxygen produces a visible colour change when reduced phenolphthalein is oxidised.

The Kastle-Meyer reagent was prepared by mixing phenolphthalein $(2 \mathrm{~g})$, potassium hydroxide (20 g), zinc powder (20 $\mathrm{g})$ and $100 \mathrm{ml}$ of distilled water in a conical flask. The solution was boiled until colourless and stored over powdered zinc in a light-resistant glass bottle at $4^{\circ} \mathrm{C}$.

Defibrinated horse blood (TCS Biosciences, Botolph Claydon, Bucks) was diluted in $0.5 \mathrm{M}$ potassium hydroxide in concentrations ranging from 0 to $450 \mathrm{ppm}$, (volumes of 0 to $4.5 \mu \mathrm{l}$ ). Duplicate $1 \mathrm{ml}$ samples of six known concentrations were placed into $1 \mathrm{ml}$ plastic cuvettes. A $50 \mu \mathrm{l}$ volume of Kastle-Meyer reagent was added to each sample and mixed by covering the cuvette with parafilm and inverting four times. Addition of $50 \mu \mathrm{l}$ of $3 \%$ hydrogen peroxide, mixed with the sample in a similar fashion, initiated the reaction. The cuvette was then placed in a spectrophotometer (CE2021, Cecil Instruments Ltd, Cambridge, UK). Absorbance readings at a wavelength of $555 \mathrm{~nm}$ were taken for each sample after $70 \mathrm{~s}$ and a standard curve of absorbance against blood volume in the range $0-450 \mu$ l was constructed. Horse blood contains approximately the same concentration of haemoglobin as human blood, ${ }^{12}$ hence the standard curve was directly used to estimate the blood volume of test samples.

\section{Matrix bands}

The matrix band retainers used in this study were of the wide Siqveland design, threaded with wide bands (Unodent, Witham, Essex). All bands were threaded by the same operator to maintain a uniform loop size.

\section{Decontamination assay}

Three series of experiments were conducted: on assembled Siqveland matrix bands artificially contaminated with defibrinated horse blood, on clinically contaminated assembled Siqveland matrix bands and on clinically contaminated matrix band retainers, after removal of the band. In each experiment, 20 contaminated instruments were subjected to one of the cleaning methods under investigation and a further group of 20 contaminated items, not subjected to any cleaning technique, were used as a control. The contaminated instruments were randomly allocated to either the control group or one of the decontamination methods.

Assembled Siqveland matrix bands were dipped in defibrinated horse blood to a depth of $1.5 \mathrm{~cm}$, sufficient to coat the loop and to cover the most tightly wound part of the assembly. The blood was allowed to air dry onto the matrix bands overnight and each band placed, working end down, into a separate $20 \mathrm{ml}$ plastic universal bottle (Sterilin, Barloworld Scientific, Stone, Staffordshire). Clinically contaminated bands were collected by ten general dental practitioners after use during restorative procedures. Immediately after treatment, each band was placed aseptically into a $20 \mathrm{ml}$ plastic universal bottle for transport to the laboratory.
Blood was recovered by pipetting $10 \mathrm{ml}$ of $0.5 \mathrm{M}$ potassium hydroxide solution into each universal bottle and then vortexing the contents for $30 \mathrm{~s}$. Where the blood concentration fell outside the range of the standard curve, the contents were further diluted with $0.5 \mathrm{M}$ potassium hydroxide. Duplicate 1 $\mathrm{ml}$ samples from each universal bottle were subjected to testing by the Kastle-Meyer method described above. The absorbance was read for each sample at $555 \mathrm{~nm}$ after $70 \mathrm{~s}$. The mean absorbance was calculated by adding the two values together and dividing by two. The volume of blood for each sample was estimated by finding the equivalent absorbance on the standard curve.

\section{DECONTAMINATION METHODS}

\section{Enzymatic agent}

Enzymatic agents contain enzymes that digest organic debris and detergents to lift contaminants into solution. The effectiveness of soaking in Alkazyme (Alkapharm UK, Penkridge, Staffordshire) was tested. A solution of Alkazyme was prepared by dissolving the powder in warm tap water at the concentration recommended by the manufacturer. Contaminated matrix bands were immersed in the solution for $5 \mathrm{~min}$, in accordance with the manufacturer's instructions. After soaking, the bands were rinsed under running tap water before being placed into separate $20 \mathrm{ml}$ plastic universal bottles. Residual blood was recovered as described above.

\section{Washer-disinfector}

Washer-disinfectors for use in medical and dental practices are designed to remove debris from instruments and then to disinfect them by raising the temperature to a level that inactivates vegetative micro-organisms. The machine tested was the Miele G 7830 TD (Eschmann Equipment, Lancing, West Sussex). The machine was installed, commissioned and validated according to HTM2030 and subjected to daily tests as required. Manufacturer's instructions were followed throughout processing. The agents used in the machine were ThermoDent liquid (Schulke and Mayr GmbH, Norderstedt, Germany), whose ingredients include ionic and non-ionic surfactants and ethanol, and ThermoDent neutralizer containing citric acid. Matrix bands were processed in the wire baskets provided on the lower shelf of the washer-disinfector. The efficacy of pre-soaking in Alkazyme followed by cleaning in the washer-disinfector was also tested. Each band or retainer was then placed separately into a sterile $20 \mathrm{ml}$ plastic universal bottle and residual blood was recovered as described above.

\section{Instrument washer}

The instrument washer tested was the Hydrim C51w (SciCan, Toronto, Ontario, Canada). This automated instrument cleaner differs from a washer-disinfector because it has no thermal disinfection cycle. The cleaning agent used was CS-C51w, containing $2 \%(\mathrm{v} / \mathrm{v})$ hydrogen peroxide. Installation, commissioning and validation were carried out by the manufacturer and their daily maintenance schedule adhered to throughout. The manufacturer's guidance was followed during the cleaning process. The machine allows the user to select a regular or heavy-duty cycle. The matrix bands artificially contaminated with horse blood were processed using each of these cycles, with and without pre-soaking in Alkazyme. 
Clinically contaminated bands and retainers were processed using the heavy duty cycle with and without pre-soaking in Alkazyme. Each assembled matrix band or retainer was placed into a separate sterile $20 \mathrm{ml}$ plastic universal bottle and blood contamination was recovered using the method outlined above.

\section{Statistical analysis}

The data were entered into an SPSS $^{13}$ database and analysed. A Kolmorogov-Smirnov test was conducted to establish whether the data was normally distributed. Non-parametric tests (Kruskal-Wallis and Mann-Whitney) were used to investigate statistical differences between residual blood volumes remaining on matrix bands following each pre-sterilisation cleaning method.

\section{RESULTS}

Artificially contaminated assembled Siqveland matrix bands

The median volume of defibrinated horse blood recovered from the assembled matrix bands in the control group was $48 \mu \mathrm{l}$ (range 20-131 $\mu \mathrm{l}$ ). Soaking in Alkazyme produced an $80.6 \%$ reduction in the median blood volume recovered compared to the control group. The reduction in median blood volume achieved by a regular cycle in the Hydrim C51W instrument washer was $92.9 \%$ and by a heavy-duty cycle was 98.4\%. The Miele G7830TD washer-disinfector produced a reduction of 99.7\%. Pre-soaking in Alkazyme before automatic processing further reduced the volume of blood recovered; with a decrease of $97.9 \%$ after a regular cycle in the instrument washer, 99.5\% following a heavy-duty cycle and $99.8 \%$ after processing in the washer-disinfector. These results and the range and median blood volumes recovered are summarised in Table 1.

Clinically contaminated assembled Siqveland matrix bands

The median volume of blood recovered from the assembled matrix bands in the control group was $0.688 \mu$ l (range 0.13$7.1 \mu \mathrm{l})$. The reduction in the median blood volume recovered

\begin{tabular}{|c|c|c|}
\hline Decontamination method & $\begin{array}{l}\text { Median (range) } \\
\text { of blood volume } \\
\text { recovered } \\
(\mu l)(n=20)\end{array}$ & $\begin{array}{l}\text { Percentage } \\
\text { reduction in } \\
\text { median blood } \\
\text { volume }\end{array}$ \\
\hline Control (no cleaning) & $48.00(20.00-131.00)$ & - \\
\hline Alkazyme & $9.300(4.10-26.30)$ & 80.6 \\
\hline Hydrim C51W regular cycle & $3.375(1.35-13.55)$ & 92.9 \\
\hline $\begin{array}{l}\text { Hydrim C51W } \\
\text { heavy-duty cycle }\end{array}$ & $0.780(0.180-1.825)$ & 98.4 \\
\hline $\begin{array}{l}\text { Miele G7830TD } \\
\text { washer-disinfector }\end{array}$ & $0.134(0.025-0.465)$ & 99.7 \\
\hline $\begin{array}{l}\text { Alkazyme + Hydrim C51W } \\
\text { regular cycle }\end{array}$ & $0.979(0.158-1.940)$ & 97.9 \\
\hline $\begin{array}{l}\text { Alkazyme + Hydrim C51W } \\
\text { heavy-duty cycle }\end{array}$ & $0.249(0.058-1.632)$ & 99.5 \\
\hline $\begin{array}{l}\text { Alkazyme + Miele G7830TD } \\
\text { washer-disinfector }\end{array}$ & $0.108(0.047-0.515)$ & 99.8 \\
\hline
\end{tabular}

compared to the control group after soaking in Alkazyme was 86.2\%. A heavy-duty cycle in the Hydrim C51W instrument washer produced a reduction of $95.3 \%$ and processing in the Miele G7830TD washer-disinfector reduced the median blood volume recovered by $91.4 \%$. Pre-soaking in Alkazyme before automatic processing further reduced the volume of blood recovered; with a decrease of 96.4\% following a heavy-duty cycle in the instrument washer and 94.3\% after processing in the washer-disinfector. These results and the range and median blood volumes recovered are summarised in Table 2 .

\section{Clinically contaminated Siqveland matrix retainers}

The median volume of blood recovered from the retainers in the control group was $0.029 \mu \mathrm{l}$ (range 0.001-1.523 $\mu \mathrm{l}$ ). Soaking in Alkazyme produced a reduction in the median blood volume recovered compared to the control group of $72.4 \%$. Processing in the Miele G7830TD washer-disinfector reduced the median blood volume recovered by 93.1\%. Pre-soaking in Alkazyme prior to processing in the washer-disinfector achieved a reduction of 89.7\%. A heavy-duty cycle in the Hydrim C51W instrument washer, with or without pre-soaking in Alkazyme produced a 100\% reduction in the median blood volume

\begin{tabular}{|c|c|c|}
\hline Decontamination method & $\begin{array}{l}\text { Median (range) } \\
\text { of blood volume } \\
\text { recovered } \\
(\mu l)(n=20)\end{array}$ & $\begin{array}{l}\text { Percentage } \\
\text { reduction in } \\
\text { median blood } \\
\text { volume }\end{array}$ \\
\hline Control (no cleaning) & $0.688(0.130-7.100)$ & - \\
\hline Alkazyme & $0.095(0.015-0.312)$ & 86.2 \\
\hline $\begin{array}{l}\text { Hydrim C51W } \\
\text { heavy-duty cycle }\end{array}$ & $0.032(0-0.199)$ & 95.3 \\
\hline $\begin{array}{l}\text { Miele G7830TD } \\
\text { washer-disinfector }\end{array}$ & $0.059(0.025-0.465)$ & 91.4 \\
\hline $\begin{array}{l}\text { Alkazyme + Hydrim C51W } \\
\text { heavy-duty cycle }\end{array}$ & $0.025(0-0.078)$ & 96.4 \\
\hline $\begin{array}{l}\text { Alkazyme + Miele G7830TD } \\
\text { washer-disinfector }\end{array}$ & $0.039(0-0.134)$ & 94.3 \\
\hline
\end{tabular}

Table 3 Median and range of blood volume $(\mu \mathrm{l})$ recovered from clinically contaminated Siqveland matrix retainers following five presterilisation cleaning methods and percentage reduction in median blood volume

\begin{tabular}{|l|l|l|}
\hline Decontamination method & $\begin{array}{l}\text { Median (range) } \\
\text { blood volume } \\
\text { recovered } \\
(\mu \mathrm{l})(\mathrm{n}=20)^{*}\end{array}$ & $\begin{array}{l}\text { Percentage } \\
\text { reduction in } \\
\text { median volume of } \\
\text { recovered blood }\end{array}$ \\
\hline Control (no cleaning) & $0.029(0.001-1.523)$ & - \\
\hline Alkazyme & $0.008(0-0.063)$ & 72.4 \\
\hline $\begin{array}{l}\text { Hydrim C51W } \\
\text { heavy-duty cycle }\end{array}$ & $0(0-0.012)$ & 100 \\
\hline $\begin{array}{l}\text { Miele G7830TD } \\
\text { washer-disinfector }\end{array}$ & $0.002(0-0.015)$ & 93.1 \\
\hline $\begin{array}{l}\text { Alkazyme + Hydrim C51W } \\
\text { heavy-duty cycle }\end{array}$ & $0(0-0.016)$ & 100 \\
\hline $\begin{array}{l}\text { Alkazyme + Miele G7830TD } \\
\text { washer-disinfector }\end{array}$ & $0.003(0-0.028)$ & 89.7 \\
\hline \begin{tabular}{l} 
*except Alkazyme + Hydrim C51W, Alkazyme + Miele G7830TD, where $n=21$ \\
\hline
\end{tabular}
\end{tabular}


recovered. These results and the range and median blood volumes recovered are summarised in Table 3.

\section{Statistical analysis}

The Kolmogorov-Smirnov test showed that the data were not normally distributed, therefore non-parametric tests were conducted to compare the median blood volumes recovered for the different pre-sterilisation cleaning methods. Kruskal-Wallis tests comparing the cleaning methods for both artificially and clinically-contaminated matrix bands and retainers showed a statistically significant difference $(\mathrm{p}<0.001)$ in the median blood volumes recovered between all the techniques tested. Comparison of the median blood volumes recovered for each cleaning method was done using a series of Mann-Whitney tests. By comparing medians, it was possible to show which pre-sterilisation cleaning method provided the greater reduction in blood volume recovered.

\section{Artificially contaminated assembled Siqveland matrix bands}

Soaking in Alkazyme or processing through the Hydrim C51w instrument washer on a regular cycle were significantly less effective ( $\mathrm{p}<0.001)$ than all the other methods tested. Processing in the Miele G7830TD washer-disinfector was significantly more effective than a heavy-duty cycle in the Hydrim C51w instrument washer ( $p<0.001)$, pre-soaking in Alkazyme followed by a regular cycle in the instrument washer $(p<0.001)$ or pre-soaking in Alkazyme followed by a heavy-duty cycle in the instrument washer $(\mathrm{p}=0.003)$. Pre-soaking in Alkazyme followed by a heavy-duty cycle in the instrument washer was significantly more effective $(p=0.001)$ than the same process without pre-soaking. Pre-soaking in Alkazyme prior to processing in the Miele washer-disinfector did not significantly improve the effectiveness of the washer-disinfector.

\section{Clinically contaminated assembled Siqveland matrix bands}

Pre-soaking in Alkazyme followed by a heavy-duty cycle in the Hydrim instrument washer was the most effective method for cleaning clinically contaminated assembled matrix bands. This method was significantly more effective than soaking in Alkazyme ( $p=0.001)$ or processing in the Miele washer-disinfector $(p=0.001)$. Without pre-soaking, there was no significant difference between processing in the washer-disinfector or the instrument washer. Pre-soaking in Alkazyme prior to processing in the Miele washer-disinfector did not significantly improve the effectiveness of the process.

\section{Clinically contaminated Siqveland matrix retainers}

The most effective method was pre-soaking in Alkazyme followed by a heavy-duty cycle in the Hydrim instrument washer. This process was significantly more effective than soaking in Alkazyme ( $p<0.001)$ or the washer-disinfector $(p=0.016)$. Presoaking in Alkazyme prior to processing in the Miele washerdisinfector did not significantly improve effectiveness.

\section{DISCUSSION}

It is accepted that gross contamination by blood, saliva and dental materials may impair the sterilisation process by insulating blood-borne pathogens. ${ }^{14}$ Removal of blood from contaminated dental instruments is of paramount importance in protecting patients from the risk of cross-infection. The serum of HBV infected patients may contain $10^{8}-10^{10}$ viral genomes per ml. ${ }^{15}$ The infective dose may be as little as $10^{4}$ viral genomes per $\mathrm{ml}$ and therefore transfer of as little as 0.1 $\mu \mathrm{l}$ of infected blood may be sufficient to transmit hepatitis B. ${ }^{16,17}$ In this study, blood contamination was found on every clinically-contaminated Siqveland matrix band and retainer tested. The largest volume of blood recovered from a clinically-contaminated assembled Siqveland matrix band was 7.1 $\mu l$, greatly exceeding the volume of infected blood necessary to transmit HBV.

The Kastle-Meyer technique has been used as a presumptive test for the presence of blood in several previous studies. ${ }^{8,12,18-}$ ${ }^{20}$ The method used in these investigations involved sampling test items by wiping the point of a folded piece of filter paper over their surface; the Kastle-Meyer test was then done on the filter paper. This method, though capable of detecting a 1:6,400 dilution of horse or sheep blood, may fail to detect blood should a contaminated area not be sampled..$^{12}$ A previous study of Siqveland matrix bands that had been decontaminated by either manual cleaning or ultrasonication did not detect residual blood on most of the instruments tested using the filter paper method. ${ }^{7}$ Our study detected residual blood on every clinically-contaminated assembled Siqveland matrix band, even after processing in a washer-disinfector. Washer disinfectors have been shown to be more effective than both manual and ultrasonic cleaning for pre-sterilisation cleaning of dental instruments. ${ }^{10,21}$ Modification of the Kastle-Meyer technique by vortexing instruments in $0.5 \mathrm{M}$ potassium hydroxide therefore improves the sensitivity of the test. In addition, use of the modified method allows accurate estimation of the volume of blood present that is not possible when using the filter paper technique.

The majority of studies comparing the efficacy of decontamination methods for dental instruments involve the use of an artificial contaminant, in many cases immersion of the test instrument in blood. ${ }^{22,23}$ Artificial contamination enables a known quantity of contaminant to be applied, allowing for accurate measurement of the effectiveness of the chosen cleaning method to be compared against a known control. For artificial contamination to be an appropriate method for testing decontamination, the results from artificially and clinically contaminated instruments should be similar. In our study, both artificially and clinically soiled instruments were tested. The results from those instruments that were dipped in blood differ from those where clinically contaminated instruments were investigated. Processing in the washer-disinfector was significantly more effective than all methods apart from pre-soaking in Alkazyme followed by a heavy-duty cycle in the instrument washer for artificially contaminated instruments. Conversely, for clinically soiled instruments, pre-soaking in Alkazyme followed by a heavyduty cycle in the instrument washer was the most effective method of pre-cleaning.

Pre-soaking of contaminated instruments enhances the effectiveness of the pre-sterilisation cleaning process because debris allowed to dry onto instruments is usually more difficult to remove. ${ }^{23,24}$ Enzymatic agents also greatly reduce the numbers of viable micro-organisms making the handling of pre-soaked instruments less hazardous for surgery staff. ${ }^{25}$

Manufacturers routinely use artificial contaminants to test 
the efficacy of their decontamination products. Results from this study indicate that cleaning methods may perform differently when processing clinically soiled instruments and that perhaps manufacturers should include the cleaning of clinically contaminated instruments in future trials.

\section{CONCLUSIONS AND RECOMMENDATIONS}

It is not possible to decontaminate assembled Siqveland matrix bands using any method currently available to dental practitioners. Once the band is removed, all detectable blood can be removed from the retainer by pre-soaking in an enzymatic detergent followed by processing in an instrument washer. Practitioners should discard matrix bands after use on one patient.

The authors would like to thank the British Dental Association Shirley Glasstone Hughes Memorial Prize fund for supporting this project.

1. British Dental Association. Advice sheet A12, Infection control in dentistry. London: BDA, 2003.

2. Centers for Disease Control and Prevention. Guidelines for infection control in dental health-care settings - 2003. MMWR Recomm Rep 2003; 52 (RR-17): 1-61.

3. Drescher J, Wagner D, Haverich A et al. Nosocomial hepatitis B virus infections in cardiac transplant recipients transmitted during transvenous endomyocardial biopsy. J Hosp Infect 1994; 26: 81-92.

4. Dumpis U, Kovalova Z, Jansons J et al. An outbreak of HBV and HCV infection in a paediatric oncology ward: epidemiological investigations and prevention of further spread. J Med Virol 2003; 69:331-338.

5. Comstock R D, Mallonee S, Fox J L et al. A large nosocomial outbreak of hepatitis $\mathrm{C}$ and hepatitis $\mathrm{B}$ among patients receiving pain remediation treatments. Infect Control Hosp Epidemiol 2004; 25: 576-583.

6. Yerly $\mathrm{S}$, Quadri R, Negro F et al. Nosocomial outbreak of multiple bloodborne viral infections. J Infect Dis 2001; 184: 369-372.

7. Lowe A H, Burke F T J McHugh S, Bagg J. A survey of the use of matrix bands and their decontamination in general dental practice. Br Dent J 2002; 192: 40-42.

8. Lowe A H, Bagg J, Burke F J, MacKenzie D, McHugh S. A study of blood contamination of Siqveland matrix bands. Br Dent J 2002; 192: 43-45.

9. Glaister J. The Kastle-Meyer test for the detection of blood. Br Med J 1926; 10: $650-652$.

10. Whitworth C L, Martin M V, Gallagher M, Worthington H V. A comparison of decontamination methods used for dental burs. Br Dent J 2004; 197: 635-640.

11. Fulford M R, Ireland A J, Main B G. Decontamination of tried-in orthodontic molar bands. Eur J Orthod 2003; 25: 621-622.

12. Edmunds $L M$, Rawlinson $A$. The effect of cleaning on blood contamination in the dental surgery following periodontal procedures. Aust Dent J 1998; 43: 349-353.

13. Statistical package for social sciences for Windows [program]. 11.0.0 version. Chicago: SPSS, 2001.

14. Miller C. Instrument cleaning involves multiple steps. Dentist 1990; 68: 23-25.

15. Lee W M. Hepatitis B infection. N Eng/ J Med 2005; 337: 1733-1745.

16. Ballard $A L$, Boxall $E H$. Assessing the infectivity of hepatitis $B$ carriers. Commun Dis Public Health 1999; 2: 178-183.

17. Barker L F, Shulman N R, Murray R et al. Transmission of serum hepatitis. J Am Med Assoc 1970; 211: 1509-1512.

18. Barton P M, M.V. Incidence of occult blood in hospital orthodontic practice. J Dent Res 1995; 74: 887.

19. McColl $E$, Bagg J, Winning $S$. The detection of blood on dental surgery surfaces and equipment following dental hygiene treatment. Br Dent J 1994; 176: 65-67.

20. Letters S, Smith A J, McHugh S, Bagg J. A study of visual and blood contamination on reprocessed endodontic files from general dental practice. Br Dent J 2005; 199: 522-525.

21. Macdonald G. Can the thermal disinfector outperform the ultrasonic cleaner? J Am Dent Assoc 1996; 127: 1787-1788.

22. Sanchez $E$, Macdonald G. Decontaminating dental instruments: testing the effectiveness of selected methods. J Am Dent Assoc 1995; 126: 359-366.

23. Kneedler $\lrcorner A$, Darling $M H$. Using an enzymatic detergent to prerinse instruments. A research study. AORNJ 1990; 51: 1326-1332.

24. Miller C. Cleaning, sterilization and disinfection: basics of microbial killing for infection control. J Am Dent Assoc 1993; 124: 48-56.

25. Bettner M D, Beiswanger M A, Miller C H, Palenik C J. Effect of ultrasonic cleaning on microorganisms. Am J Dent 1998; 11: 185-188. 